\title{
CLINICAL EVALUATION OF SELF-ADHERING FLOWABLE COMPOSITE IN NON-CARIOUS CERVICAL LESIONS
}

\author{
Enas Metwally Mahmoud Abusamra* , Mahmoud Mohamed Elsharkawy**, \\ Elsayed Mostafa Mahmoud ${ }^{* * *}$ and Waleed Abd El Meguid El Mahy****
}

\begin{abstract}
Introduction: The clinical management of non-carious cervical lesions is a challenge concerning restoring procedures because the lesions have non-retentive cavity shape and margins lying on dentin or cementum which are unfavorable for bonding.
\end{abstract}

Objective: To evaluate the clinical performance of two self-adhering flowable composites compared with flowable composite and resin modified glass ionomer in restoration of non-carious cervical lesions for 1 year.

Materials and Method: A total of 60 non-carious cervical lesions (15 for each material) were restored with self-adhering resin flowable composites (Vertise ${ }^{\mathrm{TM}}$ Flow and Fusio ${ }^{\mathrm{TM}}$ Liquid Dentin), flowable composite with ExciTE F dental adhesive system and resin modified glass ionomer. The outer surface of the dentinal wall was roughened with a water-cooled high-speed diamond bur. Occlusal or incisal enamel margins were beveled, and no mechanical retention was performed. The restorations were re-evaluated with the modified United States Public Health Services (USPHS) criteria at baseline, 3,6 and 12 months.

Results: After 1 year, 14 of the 15 Vertise Flow and 12 of the 15 Fusio Liquid Dentin restorations were in a clinically unacceptable condition due to retention failure. The success rates of Vertise Flow (6.7\%) and Fusio Liquid Dentin (20\%) were less when compared to the success rate $(80 \%)$ for the 2-step etch and rinse/Flowable composite and $(60 \%)$ for the resin modified glass ionomer restorations $(\mathrm{P}$-value $<0.001)$.

Conclusion: The clinical performance of the self-adhering resin flowable composites showed higher failure rate than other restorative materials after 1 year of clinical use.

KEYWORDS: self-adhesive flowable composite, non-carious cervical lesions, Flowable composite, 2-step etch and rinse, resin-modified glass-ionomer.

* Paper Proposal Submitted to the Department of Conservative Dentistry, Faculty of Dentistry-Alexandria University, In Partial Fulfillment of the Requirements of the Master of Science Degree Alexandria University

** Professor of Operative Dentistry, Faculty of Dentistry, University of Alexandria 


\section{INTRODUCTION}

Non-carious cervical lesions which may be caused by erosion, abrasion and/or abfraction are common in clinical practice. The number and size of lesions both tend to increase with age. They are commonly found on the facial aspects of the teeth. ${ }^{(1-3)}$

The clinical management of non-carious cervical lesions is a challenge concerning restoring procedures. The lesions have a non-retentive cavity shape with cervical margins lying on dentin or cementum. They are unfavorable for bonding due to the presence of high degree of sclerotic dentin with little or no enamel at the cervical margin. These hinder proper bonding. Another problem in management of non-carious cervical lesion is the difficulties in isolation, insertion, contouring, finishing and polishing procedures. ${ }^{(4-7)}$

The materials of choice indicated for restoring cervical lesions include: glass-ionomer cements, resin-modified glass-ionomer cements, compomers and composite resins. These materials avoid excessive removal of sound tooth structure to prevent further tooth structure loss and to improve esthetics. ${ }^{(3,4,8)}$

Recently, self-adhesive flowable composite resin systems as Vertise ${ }^{\mathrm{TM}}$ Flow and Fusio ${ }^{\mathrm{TM}}$ Liquid Dentin have been introduced to the market combining the properties of self-adhesion and flowability. These new composite resin systems reportedly bond to dentin and enamel without the application of an adhesive bonding agent. ${ }^{(9,10)}$

The problem is to decide which adhesive technique or material/system is adequate for noncarious cervical lesions as their treatment presents a unique challenge. Retention loss, post-operative sensitivity, marginal leakage, marginal staining, and secondary caries are a common observation among clinicians. ${ }^{(1,11,12)}$

Based on the previous knowledge, this clinical trial was to evaluate a one year clinical performance (retention, sensitivity, marginal adaptation and staining) of two self-adhering flowable composites (Vertise Flow and Fusio Liquid Dentin) compared to Tetric Evoflow flowable composite with 2-step etch and rinse, and Photac fil resin-modified glassionomer in restoration of non carious cervical lesions.

\section{MATERIALS AND METHODS}

Fifteen adult patients (age group 35-55 years) were selected. Non-carious cervical lesions were selected on the buccal surface of upper and lower canines and premolars. Each patient had at least 4 affected teeth. The inclusive criteria were: good oral hygiene, low decay index, no periodontal disease or deleterious habits and no wear facets. The patients were instructed by the conditions and objectives of the study and signed informed consent forms. ${ }^{(2,13)}$

A total of 60 non carious cervical lesions (15 lesions for each material) were restored by one operator using 4 types of restorative materials in 4 groups, group 1: Vertise Flow*, group 2: Fusio Liquid Dentin**, group 3: Tetric Evoflow flowable composite with Excite F dental adhesive ${ }^{* * *}$, and group 4: Photac Fil Quik Aplicap resin-modified glass ionomer ${ }^{* * * *}$. Compositions of materials used in this study are listed in Table (1).

All lesions were cleaned preoperatively with a flour of pumice. The outer surface of dentin was

\footnotetext{
* Kerr Dental, 1717W. Collins Ave, USA.

** Pentron Clinical Technologies, Wallingford, CT, USA.

*** Ivoclar Vivadent, Schaan, Liechtenstein.

****3 3 M ESPE, St. Paul, MN, USA.
} 
TABLE (1): Composition of the materials used in the study:

\begin{tabular}{|c|c|c|c|}
\hline MATERIALS & COMPOSITION & TYPE & MANUFACTURER \\
\hline Vertise flow & $\begin{array}{l}\text { Prepolymerised filler, barium glass, nano- } \\
\text { sized colloidal silica, nano-sized ytterbium } \\
\text { flouride, GPDM and methacrylate co- } \\
\text { monomers }\end{array}$ & $\begin{array}{l}\text { Self adhesive } \\
\text { composite }\end{array}$ & $\begin{array}{l}\text { Kerr corporation, Orange, } \\
\text { CA,USA. }\end{array}$ \\
\hline $\begin{array}{l}\text { Fusio }^{\mathrm{TM}} \text { Liquid } \\
\text { Dentin }\end{array}$ & $\begin{array}{l}\text { UDMA, TEGDMA, HEMA, 4-META, } \\
\text { Silane treated barium glass, Silica, } \\
\text { Minor additives, Photo Curing System }\end{array}$ & $\begin{array}{l}\text { Self adhesive } \\
\text { composite }\end{array}$ & $\begin{array}{l}\text { Pentron clinical } \\
\text { Technology, LLC,Wallingford, } \\
\text { CT,USA. }\end{array}$ \\
\hline Tetric EvoFlow & $\begin{array}{l}\text { Bis-GMA, UDMA, Decandioldimethacrylat, } \\
\text { Barium glass filler, Ytterbiumtrifluoride, } \\
\text { Mixed oxide, Highly dispered silica, } \\
\text { Prepolymers, Additives, Catalysts, } \\
\text { Stabilizers and Pigments. }\end{array}$ & Flowable Composite & $\begin{array}{l}\text { Ivoclar Vivadent, Schaan, } \\
\text { Liechtenstein. }\end{array}$ \\
\hline $\begin{array}{l}\text { ExciTE F dental } \\
\text { adhesive }\end{array}$ & $\begin{array}{l}\text { phosphonic acid acrylate, HEMA, } \\
\text { dimethacrylate, highly dispersed silicone } \\
\text { dixoide, initiators, stabilizers and potassium } \\
\text { fluoride in an alcohol solution. }\end{array}$ & Dental adhesive & $\begin{array}{l}\text { Ivoclar Vivadent, } \\
\text { Schaan, Liechtenstein. }\end{array}$ \\
\hline Photac Fill & $\begin{array}{l}\text { 2-Hydroxyethyl Methacrylate, copolymer } \\
\text { acrylic acid-maleic acid, water, mono and } \\
\text { di HEMA phosphate, magnesium salt and } \\
\text { diurethan dimethacrylat. }\end{array}$ & RMGICs & 3M ESPE, St. Paul, MN, USA \\
\hline
\end{tabular}

Abbreviations: GPDM, Glycerol phosphate dimethacrylate; UDMA, urethane dimethacrylate; HEMA, Hydroxyethyl methacrylate; TEGDMA, Triethylene glycol dimethacrylate; 4-META, Methacryloxyethyl trimellitic acid; Bis-GMA, bisphenol A diglycidyl methacrylate.

roughened by using a Football-shaped S-Diamond* (bud shaped, 6368-016) water-cooled high-speed diamond bur. A $1 \mathrm{~mm}$ bevel was done on the occlusal or incisal enamel margins using a tapered round end diamond (856-12) at high speed with water cooling, to increase surface area for bonding and to enhance aesthetics. No mechanical retention was performed. ${ }^{(14)}$

All restorations were performed under complete isolation by rubber dam application using the Cervical Clamp \#214**. All materials were applied incrementally according to the manufacturer's instructions.

\footnotetext{
* Komet, Gebr. Brasseler GmbH \& Co. KG.

** Ash Dental Practice, Manchester, United Kingdom.

***Being Foshan Medical Equipment Co. Ltd, China.
}

Group 1: The first layer of Vertise Flow was agitated for 20 seconds to obtain a thin layer $(<0.5 \mathrm{~mm})$ using a disposable brushes and was cured for 20 seconds using LED light curing unit**** The restoration was built with 2 or 3 layers of Vertise Flow. The restorations were finished and polished.

Group 2: The first layer of Fusio Liquid Dentin was agitated with a disposable brush for 20 seconds and cured for 20 seconds. The restoration was built with 2 or 3 layers of the restoration then finished and polished. 
Group 3: Phosphoric acid gel (37\%) was applied to the prepared enamel and dentin. The etchant was left on the enamel for 30 seconds and on dentin for 15 seconds then washed and dried. Dentin bonding agent was applied, agitated for 5 seconds and then light cured it for 20 seconds. Tetric Evoflow flowable composite was applied incrementally ( 2 or 3 layers), each increment was cured for 40 seconds. After polymerization, the restoration was finished and polished.

Group 4: Photac $^{\mathrm{TM}}$ Fil resin-modified glass ionomer. The capsule was first activated using the Aplicap $^{\text {TM }}$ Activator*. Then the capsule was mixed at approx. 4,300 rpm in a high frequency device $\left(\mathrm{CapMix}^{\mathrm{TM}}\right)$ for $10 \mathrm{sec}$. The restorative material was applied in the cavity by the Aplicap ${ }^{\mathrm{TM}}$ Applier, and then cured for $20 \mathrm{sec}$.the restoration then finished and polished.

Restorations were evaluated for their clinical performance regarding retention, sensitivity, marginal adaptation and marginal staining of the restoration according to the modified United States Public Health Services (USPHS) criteria (Table 2) at 1 day, 3, 6 and 12 months. Results were collected and statistically analyzed.

\section{Statistical analysis of the data}

Data were fed to the computer and analyzed using IBM SPSS software package version 20.0. Qualitative data were described using number and percent. Significance of the obtained results was judged at the $5 \%$ level.

TABLE (2) Modified USPHS criteria for direct evaluation of restoration and evaluation method.

\begin{tabular}{|c|c|c|c|}
\hline Evaluation criteria & Evaluation Method & Code & Definition \\
\hline $\begin{array}{l}\text { Retention of } \\
\text { restoration }\end{array}$ & $\begin{array}{l}\text { Visually (after air-drying the tooth) and } \\
\text { tactilely using a sharp probe. }\end{array}$ & $\begin{array}{l}\text { A } \\
\text { B } \\
\text { C }\end{array}$ & $\begin{array}{l}\text { Retained. } \\
\text { Partially retained. } \\
\text { Missing. }\end{array}$ \\
\hline Sensitivity & $\begin{array}{l}\text { By blowing a stream of compressed air for } \\
3 \mathrm{~s} \text { at a distance of } 2-3 \mathrm{~cm} \text {, perpendicular to } \\
\text { the surface of the tooth (while shielding the } \\
\text { adjacent teeth with piece of rubber) and at an } \\
\text { environmental temperature of } 19-24^{\circ} \mathrm{C} \text {. }\end{array}$ & $\begin{array}{l}\text { A } \\
\text { B } \\
\text { C } \\
\text { D }\end{array}$ & $\begin{array}{l}\text { None. } \\
\text { Mild but bearable. } \\
\text { Uncomfortable, but no replacement is } \\
\text { necessary. } \\
\text { Painful. Replacement of restoration necessary. }\end{array}$ \\
\hline Marginal adaptation & $\begin{array}{l}\text { Tactilely by moving a sharp probe over the } \\
\text { restorations margins. }\end{array}$ & $\begin{array}{l}\text { A } \\
\text { B } \\
\text { C }\end{array}$ & $\begin{array}{l}\text { Restoration closely adapted to the tooth. } \\
\text { No crevice visible. No explorer catch at the } \\
\text { margins, or there was a catch in one direction. } \\
\text { Explorer catch. No visible evidence of } \\
\text { a crevice into which the explorer could } \\
\text { penetrate. No dentin or base visible. } \\
\text { Explorer penetrates into a crevice that is of a } \\
\text { depth that exposes dentin or base. }\end{array}$ \\
\hline Marginal staining & Visually (after air-drying the tooth) & $\begin{array}{l}\text { A } \\
\text { B } \\
\text { C }\end{array}$ & $\begin{array}{l}\text { No staining along cavosurface margin. } \\
<50 \% \text { of cavosurface affected by stain. } \\
>50 \% \text { of cavosurface affected by stain. }\end{array}$ \\
\hline
\end{tabular}

* 3M ESPE, St. Paul, MN, USA. 
The used tests were :

1 - Chi-square test: For categorical variables, to compare between different groups.

2 - Monte Carlo correction: Correction for chisquare when more than $20 \%$ of the cells have expected count less than 5 .

\section{RESULTS}

The recall rates of patients were $100 \%$. The results of the clinical evaluations and statistical comparisons are presented in Table 3.

Regarding retention, Tetric Evoflow flowablle composite showed the best results with $80 \%$ success rate when evaluated clinically after 1 year. Photac fil resin modified glass ionomer comes next with a $60 \%$ success rate. Both self adhering composites showed higher failure rates. There success rates where $(6.7 \%$ and $20 \%)$ respectively. There was significant difference between the four groups (P-value<0.001).

Regarding post-operative sensitivity, Tetric Evoflow flowable composite exhibited the least postoperative sensitivity after 1 year [ $80 \%$ with score (A) and $20 \%$ with score (D)]; followed by Photac Fil RMGIC had (60\%) with score (A) and (40\%) with score (D). Vertise Flow and Fusio Liquid Dentin showed the lowest results $(6.7 \%$ and $20 \%)$ with score (A) respectively and $(93.3 \%$ and $80 \%)$ with score (D) respectively. There was significant difference between the four groups (P-value $<0.001)$.

For the marginal adaptation and staining, Tetric Evoflow demonstrated the best result after 1 year [73.3\% scored (A), 6.7\% scored (B) and 20\% scored (C)], followed by Photac Fil (46.7\% with score (A), $13.3 \%$ with score (B) and $40 \%$ with score (C)). The results for Fusio Liquid Dentin were [20\% with score (A), 6.7 with score (B) and $80 \%$ with score $(\mathrm{C})]$. Vertise Flow showed the lowest results [6.7\% with score (A) and $93.3 \%$ scored (C)]. There was significant difference between the four groups (P-value<0.001).

\section{DISCUSSION}

The clinical management of non-carious cervical lesion is a challenge as these lesions poses certain difficulties such as little enamel margin, presence of sclerotic dentin and difficult to isolate. ${ }^{(4,5)}$

Laboratory tests do not always reflect the behavior of the material in the clinic because of the differences between laboratory and clinical conditions. Even if laboratory tests demonstrate good results, they do not always result in good clinical performance. ${ }^{(1)}$

Non-carious cervical lesions are considered to be most ideal to determine the clinical effectiveness of adhesives because such lesions (1) are relatively abundant and on the buccal surface thus providing good access for the restorative procedure (2) do not provide any macro-mechanical retention so that ineffective bonding will result in early restoration loss, (3) do not require complicated restorative techniques, (4) can be restored with low C-factor, (5) involve both enamel and dentin. ${ }^{(9,15)}$

Regarding retention criteria, this study showed that flowable composite with 2-step etch and rinse dentin bonding agent give the best results (success rate $80 \%$ ). This may be attributed that the hydrolytic degradation of the dentin-resin interface has been overcomed. In terms of retention, flowale composite is followed by resin modified glass ionomer which had a $60 \%$ success rate. This may be attributed to its capacity of adhering to enamel and dentin. Both self-adhering composites showed the lowest results (Vertise Flow 6.7\% success rate and Fusio Liuid Dentin 20\% success rate). These results were in agreement with Çelik et al (2015) who found that success rate of Fusio Liquid Dentin is 33\% in non-carious cervical lesions after a 6 months recall period. This was explained that bond strength of self-adhering composites to be significantly lower than different adhesion mechanisms on both enamel and dentin. This is in accordance to the findig of Tuloglu et al (2014), Fu et al (2013), Poitevin et al 


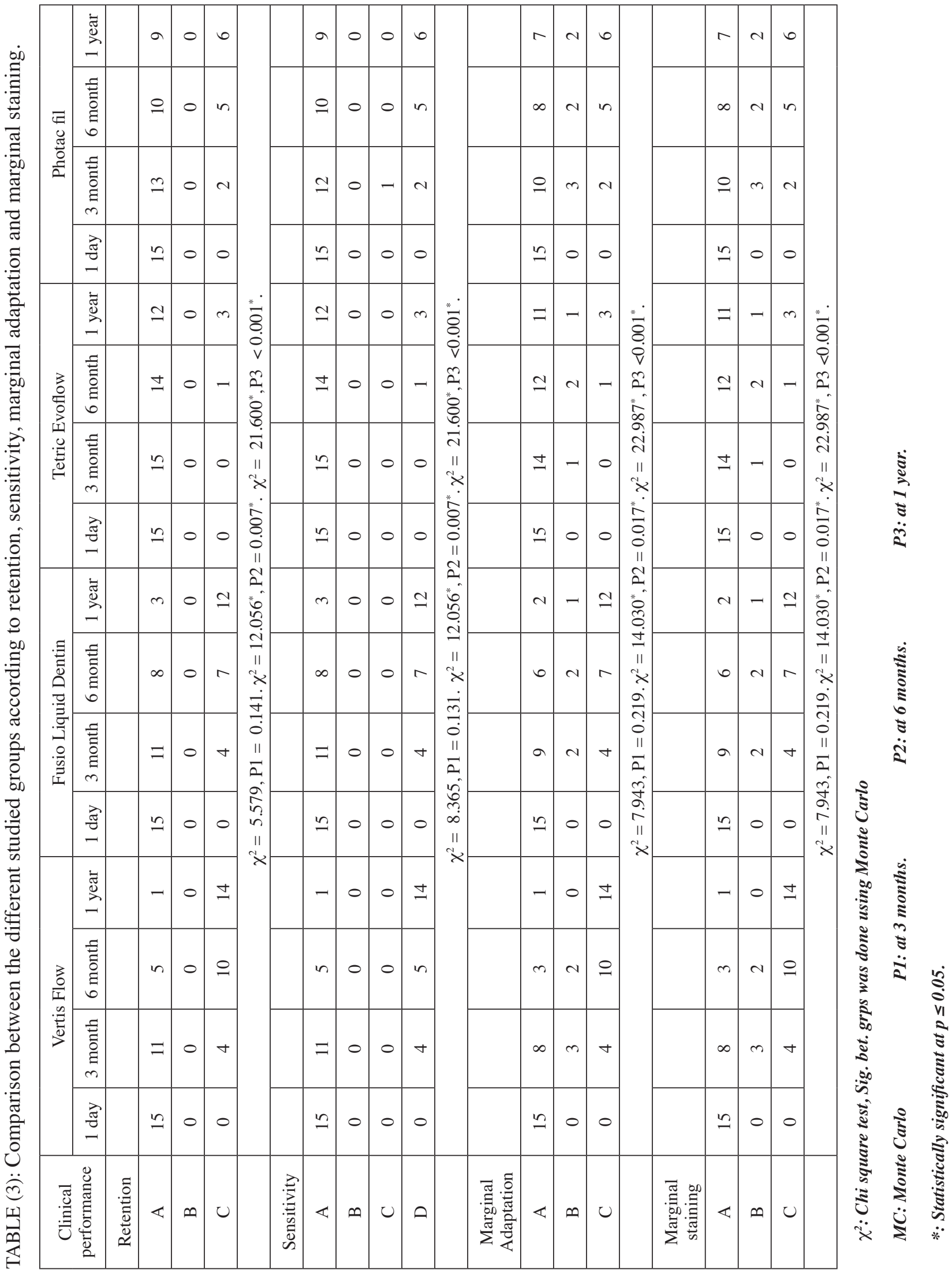


(2013) and Wajdowicz MN et al (2012). This was attributed to inadequate micromechanical retention between the restorations and tooth structure as a result of the lower etching ability of self-adhering composites. ${ }^{(2,16-21)}$

On the contrary, Vichi et al (2011) used Vertise Flow in t Class-I cavities were followed up and clinically assessed for six months. They concluded that Vertise Flow remained clinically acceptable over the 6-month follow up period. ${ }^{(22)}$

Postoperative sensitivity was not observed in this study during the 1 year examination period except for 1 restoration of Photac fil which scored $\mathrm{C}$ after 3 months. It should be noted that there was a high restoration failure rate. During statistical analysis the failed restoration had to be scored $\mathrm{D}$ while the only remaining restoration had scored A. This explaind why there was a statistically significant results between the different groups. Self-adhering composites and resin modified glass ionomers are less technique sensitive than the 2-step etch and rinse flowable composites. The manufacturers of self-adering composites claim that eliminating the need for separate etching and conditioning of the tooth substrate offers good marginal sealing, reduces the risk of over-etching and over-wetting, and that it may avoid over-drying which leads to the collapse of the collagen fiber network. The true chemical bonding of resin modified glass ionomer with the tooth structure is responsible for the absence of postoperative sensitivity. ${ }^{(16,23,24)}$

This result is in agreement with Pinna et al (2015) and Vichi et al (2011) who reported that Vertise Flow showed no post-operative sensitivity. Hanabusa et al (2011) conducted a study using scaning electron microscope (SEM) and showed that the Vertise Flow layer covered the exposed surface of dentine leading to tubular sealing and reduction of sensitivity. Also according to Abo El Naga et al (2015), it was found that the sealability of Fusio Lquid Dentin was better than self-adhesives. ${ }^{(21,25-27)}$
According to this study, regarding marginal adaptation and staining, Tetric Evoflow demonstrated best clinical results. Self-dhering composites also had clinically accepted marginal adaptation. During statistical analysis the failed restoration had to be scored $\mathrm{C}$ while the only remaining restoration had scored A and B. This explaind why there was a statistically significant results between the different groups. Bektas et al (2013) and Rengo et al (2012) reported a similar sealing ability of self-adering composites to the etch-and-rinse adhesives in enamel and dentin. These results are in agreement with Celik et al (2015) and Vichi et al (2011) who reported acceptable marginal adaptation and superficial marginal discolorations. Slightly dull surfaces were observed in both self-adering composites when compared with different adhesion mechanisms. ${ }^{(16,21,28,29)}$

\section{CONCLUSION}

Self-adhering composites showed higher failure rate than other restorative materials after 1 year of clinical use in non-carious cervical lesions.

\section{REFRENCES}

1. Kubo S, Kawasaki K, Yokota H, Hayashi Y. Five-year clinical evaluation of two adhesive systems in non-carious cervical lesions. J Dent 2006; 34: 97-105.

2. Santiago SL, Passos VF, Vieira AH, Navarro MF, Lauris JR, Franco EB. Two-Year Clinical Evaluation of Resinous Restorative Systems in Non-Carious Cervical Lesions. Braz Dent J 2010; 21: 229-34.

3. Peumans M, De Munck J, van Landuyt KL, Poitevin A, Lambrechts P, van Meerbeek B. Eight-year clinical evaluation of a 2-step self-etch adhesive with and without selective enamel etching. Dent Mater 2010; 26: 1176-84.

4. Perez Cdos R, Gonzalez MR, Prado NA, de Miranda MS, Macêdo Mde A, Fernandes BM. Restoration of Noncarious Cervical Lesions:When,Why, and How. Int J Dent 2012; 2012: 687058 .

5. Ichim IP, Schmidlin PR, Li Q, Kieser JA, Swain MV. Restorative material selection to minimize fracture. Dent Mater 2007; 23: 1562-9. 
6. Irfan Ahmad UK. Compobond: Evolution of a new restorative dental material. Cosm dent 2011; 2: 26-37.

7. Arslan S, Demirbuga S, Ustun Y, Dincer AN, Canakci BC, Zorba YO. The effect of a new-generation flowable composite resin on microleakage in Class $\mathrm{V}$ composite restorations as an intermediate layer. J Conserv Dent 2013; 16:189-93.

8. Magni E, Radovic I, Papacchini F, Mazzitelli C. Bonding of self- etching adhesivelflowable composite combinations to enamel and dentin: A microtensile bond strength evaluation. Int Dent SA 2007; 9: 6-18.

9. Van Meerbeek B, Peumans M, Poitevin A, Mine A, A. Van Ende, A. Neves et al. Relationship between bondstrength tests and clinical outcomes. Dent Mater 2010; 26:e100-e121.

10. Erdemir U, Sancakli HS, Sancakli E, Eren MM, Ozel S, Yucel $\mathrm{T}$ et al. Shear bond strength of a new self-adhering flowable composite resin for lithium disilicate-reinforced CAD/CAM ceramic material. J Adv Prosthodont 2014; 6: 434-43.

11. Siegward D. Heintze. Clinical relevance of tests on bond strength, Microleakage and marginal adaptation. Dent Mater 2013; 29: 59-84.

12. Narayanaswamy S, Meena N, Shetty A, Kumari A, Naveen DN. Finite element analysis of stress concentration in class $\mathrm{V}$ restorations of four groups of restorative materials in mandibular premolars. J Conserv Dent 2008; 11: 121-6.

13. da Rosa Rodolpho PA, Cenci MS, Donassollo TA, Loguércio AD, Demarco F. A clinical evaluation of posterior composite restorations: 17-year findings. J Dent 2006; 34 : 427- 35 .

14. Kubo S, Yokota H, Yokota H, Hayashi Y. Two-year clinical evaluation of one-step self-etch systems in non-carious cervical lesions. J Dent 2009; 37: 149-155.)

15. M. Peumans, J. De Munck, A. Mine, B. Van Meerbeek. Clinical effectiveness of contemporary adhesives for the restoration of non-carious cervical lesions. A systematic review. Dent Mater 2014; 30: 1089-1103.

16. Celik EU, Akab B, Yilmazc F. Six-month Clinical Evaluation of a Self-adhesive Flowable Composite in Noncarious Cervical Lesions. J Adhes Dent 2015; 17: 361-368.

17. Tuloglu N, Tunc ES, Ozer S, Bayrak S. Shear bond strength of self-adhering flowable composite on dentin with and without application of an adhesive system. J Appl Biomater Funct Mater 2014; 12: 97-101.
18. Fu J, Kakuda S, Pan F, Hoshika S, Ting S, Fukuoka A et al. Bonding performance of a newly developed step-less allin-one system on dentin. Dent Mater J 2013; 32: 203-211.

19. Poitevin A, De Munck J, Van Ende A, Suyama Y, Mine A, Peumans $\mathrm{M}$ et al. Bonding effectiveness of self-adhesive composites to dentin and enamel. Dent Mater. 2013; 29: 221-30.

20. Wajdowicz MN, Vandewalle KS, Means MT. Shear bond strength of new self-adhesive flowable composite resins. Gen Dent 2012;60 :e104-8.

21. De Munck J, Van Meerbeek B, Yoshida Y, Inoue S, Vargas M, Suzuki K, et al. Four-year water degradation of total-etch adhesives bonded to dentin. J Dent Res. 2003; 82:136-40.

22. Vichi A, Goracci C, Ferrari M. Clinical study of the selfadhering flowable composite resin Vertise Flow in Class I restorations: six-month follow-up. Int Dent SA 2011; 12: 14-23.

23. Yazici AR, Agarwal I, Funollet MC, Viveros CM, Antonson SA, Antonson DE, et al. Effect of laser preparation on bond strength of a self-adhesive flowable resin. Lasers Med Sci 2013; 28:343-347.

24. Jyothi KN, Annapurna S, Anil Kumar S, Venugopal P, Jayashankara CM. Clinical evaluation of giomer- and resin-modified glass ionomer cement in class $\mathrm{V}$ noncarious cervical lesions: An in vivo study. J conserv Dent 2011; 14: 409-413.

25. Hanabusa M, Mine A, Kuboki T, Momoi Y, Van Landuyt KL, Van Meerbeek B, et al. TEM interfacial characterization of an experimental self-adhesive filling material bonded to enamel/dentin. Dent Mat 2011; 27: 818-824.

26. Abo El Naga A, Yousef M, Ramadan R, Bahgat SF, Alshawwa L. Does the use of a novel self-adhesive flowable composite reduce nanoleakage?. Clin Cosm Invest Dent 2015; 7: 55-64.

27. Pinna R, Bortone A, Sotgiu G, Dore S, Usai P, Milia E. Clinical evaluation of the efficacy of one self-adhesive composite in dental hypersensitivity. Clin Oral Invest 2015; 19:1663-1672.

28. Rengo C, Goracci C, Juloski J, Chieffi N, Giovannetti A, Vichi A, et al. Influence of phosphoric acid etching on microleakage of a self-etch adhesive and a self-adhering composite. Aust Dent J 2012; 57: 220-226.

29. Bektas O, Eren D, Akin EG, Akin H. Evaluation of a self-adhering flowable composite in terms of micro-shear bond strength and microleakage. Acta Odonto Sca, 2013; 71: 541-546. 